\title{
Baseline lymphopenia as prognostic factor in patients with metastatic breast cancer treated with palbociclib
}

\author{
GEORGE EMILE $^{1}$, SARAH PENAGER ${ }^{2}$, CHRISTELLE LEVY $^{1}$, ALISON JOHNSON ${ }^{1}$, DJELILA ALLOUACHE ${ }^{1}$, \\ JUSTINE LEQUESNE ${ }^{2}$, IOANA HRAB ${ }^{1}$, CARINE SEGURA $^{1}$, ADELINE MOREL ${ }^{1}$, KATARINA GUNZER ${ }^{1}$, \\ AUDREY FAVEYRIAL ${ }^{1}$, FRANCOIS CHERIFI ${ }^{1}$ and ANGELIQUE DA SILVA ${ }^{1}$ \\ ${ }^{1}$ Breast Cancer Unit, François Baclesse Comprehensive Cancer Center; ${ }^{2}$ Clinical Research Department, \\ François Baclesse Comprehensive Cancer Center, Caen, Calvados, Normandy 14000, France
}

Received June 4, 2021; Accepted September 13, 2021

DOI: $10.3892 / \mathrm{ol} .2021 .13143$

\begin{abstract}
Cyclin-dependent-kinase 4-6 inhibitors (CDK4/6i) have improved the management of hormone receptor $(\mathrm{HR})^{+} /$human epidermal growth factor receptor (HER)2 metastatic breast cancer $(\mathrm{mBC})$. Currently, there are no valid prognostic factors for response to CDK4/6i. Baseline lymphopenia is reported as a prognostic factor in several types of cancer. The present retrospective study aimed to evaluate the effect of baseline absolute lymphocyte count (ALC) on response to palbociclib. Progression-free survival (PFS) was the primary endpoint. Secondary endpoints were overall survival (OS), best response and safety. A total of 114 patients treated for mBC between 2016 and 2019 were included. Median baseline ALC was $1.4 \mathrm{~g} / 1$ (range, 0.2-4.3 g/l). A total of $65(57 \%)$ and $49(43 \%)$ patients had baseline ALC values of $<1.5$ and $\geq 1.5 \mathrm{~g} / \mathrm{l}$, respectively. Patients with baseline lymphopenia exhibited significantly shorter PFS (6 vs. 10 months; $\mathrm{P}=0.004)$ and $\mathrm{OS}(20$ vs. 33 months; $\mathrm{P}=0.02)$. ALC $<1.5 \mathrm{~g} / \mathrm{l}$ independently predicted worse survival, as indicated by multivariate analysis $(\mathrm{P}=0.04$; hazard ratio, 1.76 ; $95 \%$ confidence interval, 1.02-3.02). Patients with baseline ALC $<1.5 \mathrm{~g} / 1$ had significantly less partial response (14 vs. $22 \% ; \mathrm{P}=0.016)$ and more disease progression (46 vs. $20 \% ; \mathrm{P}=0.016$ ) than those with ALC $\geq 1.5 \mathrm{~g} / 1$. ALC is a strong and easy-to-use dosage
\end{abstract}

Correspondence to: Dr George Emile, Breast Cancer Unit, François Baclesse Comprehensive Cancer Center, 3 Avenue du Général Harris, Caen, Calvados, Normandy 14000, France

E-mail: g.emile@baclesse.unicancer.fr

Abbreviations: ALC, absolute lymphocyte count; BC, breast cancer; $\mathrm{mBC}$, metastatic breast cancer; ET, endocrine therapy; CDK4/6i, cyclin dependent kinase 4-6 inhibitor; PFS, progression-free survival; $\mathrm{OS}$, overall survival; $\mathrm{AE}$, adverse event; $\mathrm{HR}^{+}$, hormone receptor-positive; HER2, human epidermal growth factor receptor 2-negative; $\mathrm{CR}$, complete response; PR, partial response; SD, stable disease; $\mathrm{PD}$, progressive disease; ORR, objective response rate; DCR, disease control rate; PS, performance status; HR, hazard ratio; TL, T lymphocytes

Key words: metastatic breast cancer, lymphopenia, cyclin dependant kinase inhibitor, palbociclib, prognosis factor with prognostic factor for patients with $\mathrm{HR}^{+} / \mathrm{HER}^{-} \mathrm{mBC}$ treated with palbociclib and endocrine therapy. Lymphopenia may also be a predictive factor of early progression. These data need to be verified in a larger prospective study.

\section{Introduction}

Breast cancer (BC) is the most frequently occurring cancer in women worldwide, with $>2$ million new cases diagnosed in 2018 (1). $770 \%$ of BC cases are hormone receptor-positive $\left(\mathrm{HR}^{+}\right)$and human epidermal growth factor receptor 2-negative (HER2'). Endocrine therapy (ET) is considered the mainstay of treatment for both pre- and postmenopausal women with $\mathrm{HR}^{+} / \mathrm{HER} 2^{-}$metastatic $\mathrm{BC}(\mathrm{mBC})$ (2). Regarding $\mathrm{mBC}$, the most relevant therapeutic improvement of the last few years has been the introduction of cyclin-dependent kinase (CDK) 4 and 6 inhibitors (CDK4/6i) (palbociclib, ribociclib and abemaciclib) combined with ET. Pivotal trials, namely PALOMA 2 and 3, MONALEESA 2, 3 and 7, and MONARCH 2 and 3, showed an improvement in progression free survival (PFS) of 5 to 10 months (3-8). A recent meta-analysis reported that CDK4/6-i + ET combinations, compared with ET alone, improved overall survival (OS) independent of age, menopausal status, endocrine sensitivity and visceral involvement (9). Except for patients with extensive visceral involvement, CDK4/6i + ET combinations remain the treatment of choice for $\mathrm{HR}^{+} / \mathrm{HER} 2^{-} \mathrm{mBC}$ (2).

Despite the significant improvements in survival determined by CDK4/6i, resistance represents a major clinical challenge. Resistance might be present immediately at treatment initiation. Primary or de novo resistance occurs in $\sim 15 \%$ of patients receiving CDK4/6i with anti-aromatase inhibitors, and $\sim 30 \%$ of those receiving CDK4/6i with fulvestrant (10). Currently, there are no valid prognostic factors for response to $\mathrm{CDK} 4 / 6 \mathrm{i}$. Baseline lymphopenia has been reported in several publications as a prognostic factor in different types of cancer (11-17). Thus, lymphopenia is an independent predictive factor of survival in metastatic colorectal cancer patient with shorter PFS (median 4 vs. 7 months; $\mathrm{P}=0.033$ ) and OS (median 16 vs. 24 months, $\mathrm{P}=0.024)(11)$.

The present study aimed to assess the impact of baseline absolute lymphocyte count (ALC) on response to CDK4/6i. 


\section{Materials and methods}

Design. Between April 2016 and February 2019, a descriptive retrospective single center study was performed at the François Baclesse Comprehensive Cancer Center, Caen, Calvados, Normandy. Eligible patients were women aged $>18$ years with $\mathrm{HR}^{+} / \mathrm{HER} 2^{-} \mathrm{mBC}$ treated with palbociclib in combination with ET (an aromatase inhibitor or fulvestrant). Premenopausal women also received luteinizing hormone-releasing hormone agonists. A total of 114 patients were included; there were no predefined exclusion criteria. The primary end-point, PFS, was evaluated from palbociclib initiation to radiological progression, death or last follow-up. Secondary end points were OS (time from palbociclib initiation to death), best radiological response and safety. Tumor assessment was performed every 2-3 cycles and disease response was categorized as complete response (CR), partial response (PR), stable disease (SD) or progressive disease (PD), according to the response evaluation criteria in solid tumors (version 1.1) (18). Objective response rate (ORR) was defined as the percentage of patients in whom either CR or PR was observed. Disease control rate (DCR) was defined as the proportion of patients with either CR, PR or $\mathrm{SD}$ as best overall response. All patients underwent baseline routine blood tests, including white blood cell and ALC. Lymphopenia was defined as ALC $<1.5 \mathrm{~g} / \mathrm{l}$; lymphopenia and other adverse events (AEs) were graded according to National Cancer Institute Common Terminology Criteria for AEs (version 5.0) (19). Initial dose of palbociclib and dose reductions were reported and analyzed for their impact on PFS and OS.

In accordance with regulations regarding research involving human subjects, the present study was registered in the corresponding data protection document. As an observational retrospective study, institutional review board approval was not required. Patients' non-opposition to the use of their data was sought after checking whether the patient was still living; as a result, no data exclusion due to death was necessary. All data were anonymized for statistical analysis.

Statistical analysis. Qualitative variables are presented as the number and frequency; quantitative variables are presented as the mean \pm standard deviation or median and extreme values. The characteristics of lymphopenic and non-lymphopenic patients were compared by $\chi^{2}$ test (or Fisher's exact test, in case of observed values per category $<5$ ) for the qualitative variables, and by the unpaired Student's t-test for the quantitative variables (or Wilcoxon non-parametric test if data were not normally distributed). $\mathrm{P}<0.05$ was considered to indicate a statistically significant difference. PFS and OS were calculated according to the Kaplan-Meier method and comparison of survival between different patient populations was performed by the log-rank or supremum log-rank test (Renyi-type test) in case of crossing curves. The impact of known prognostic factors (age, number of previous lines of treatment, palbociclib dose reduction and occurrence of $\mathrm{AE}$ ) was assessed by univariate and multivariate Cox models. All incident cases were assessed (no calculation of the number of subjects needed). Analyses were conducted using $\mathrm{R}$ software, version 4.0.2 (https://cran.r-project.org/bin/windows/base/).
Table I. Characteristics of patients.

\begin{tabular}{|c|c|c|}
\hline Characteristic & Number $(n=114)$ & $\%$ \\
\hline Median age, years (range) & $51(30-75)$ & \\
\hline \multicolumn{3}{|l|}{ PS } \\
\hline 0 & 47 & 41.2 \\
\hline 1 & 51 & 44.7 \\
\hline 2 & 13 & 11.4 \\
\hline 3 & 3 & 2.6 \\
\hline \multicolumn{3}{|l|}{ Histological diagnosis } \\
\hline Invasive lobular carcinoma & 21 & 19.6 \\
\hline Invasive ductal carcinoma & 81 & 75.7 \\
\hline Other & 5 & 4.7 \\
\hline Missing & 7 & 6.1 \\
\hline \multicolumn{3}{|l|}{ Initial stage } \\
\hline I-III & 95 & 83.3 \\
\hline $\mathrm{IV}($ de novo $)$ & 19 & 16.7 \\
\hline \multicolumn{3}{|l|}{ Hormone receptor status } \\
\hline $\mathrm{ER}^{+} / \mathrm{PR}^{+}$ & 94 & 82.5 \\
\hline $\mathrm{ER}^{+} / \mathrm{PR}^{-}$ & 19 & 16.6 \\
\hline $\mathrm{ER}^{-} / \mathrm{PR}^{+}$ & 1 & 0.9 \\
\hline \multicolumn{3}{|l|}{ Endocrine therapy } \\
\hline Fulvestrant & 97 & 85.1 \\
\hline Letrozole & 17 & 14.9 \\
\hline \multicolumn{3}{|l|}{ ALC, g/l } \\
\hline$\geq 1.50$ & 49 & 43.0 \\
\hline $1.49-0.80$ & 47 & 41.0 \\
\hline $0.79-0.50$ & 13 & 12.0 \\
\hline $0.49-0.20$ & 5 & 4.0 \\
\hline
\end{tabular}

PS, performance status; ER, estrogen receptor; PR, progesterone receptor; ALC, absolute lymphocyte count.

\section{Results}

Clinicopathological data of patients. Between April 2016 and February 2019, a total of 114 patients were recruited. The median age at palbociclib initiation was 51 years. Most patients had a good Eastern Cooperative Oncology Group performance status (PS; PS0, 41.2\%; PS1, 44.7\%). The median number of previous lines of treatment was four and $85.1 \%$ of patients received fulvestrant in combination with palbociclib. Only $16.7 \%$ of patients exhibited de novo mBC (Table I). Median baseline ALC was $1.4 \mathrm{~g} / \mathrm{l}$ (range, 0.2-4.3 g/l). A total of $65(57 \%)$ and $49(43 \%)$ patients had baseline ALC $<1.5$ and $\geq 1.5 \mathrm{~g} / \mathrm{l}$, respectively. PS, number of previous lines of treatment and palbociclib dose reduction were not significantly different in these two groups (Table II).

PFS was shorter in patients with lymphopenia. Median PFS in the whole population was 7.9 months. Patients with baseline lymphopenia had significantly shorter PFS (6 vs. 10 months; log-rank $\mathrm{P}=0.004$; Fig. 1). Univariate analysis demonstrated that age did not influence PFS. Patients who received 
Table II. Characteristics of patients according to pretreatment absolute lymphocyte count.

\begin{tabular}{|c|c|c|c|}
\hline \multirow[b]{2}{*}{ Characteristic } & \multicolumn{2}{|c|}{ Number } & \multirow[b]{2}{*}{ P-value } \\
\hline & ALC >1.5 g/l (n=49) & ALC $<1.5 \mathrm{~g} / \mathrm{l}(\mathrm{n}=65)$ & \\
\hline PS & & & 0.170 \\
\hline $0 / 1$ & $45.0(91.8 \%)$ & $53.0(81.5 \%)$ & \\
\hline $2 / 3$ & $4.0(8.2 \%)$ & $12.0(18.5 \%)$ & \\
\hline $\begin{array}{l}\text { Previous lines of treatment, } \\
\text { median (range) }\end{array}$ & $3.0(2.0-4.0)$ & $4.0(2.0-6.0)$ & 0.170 \\
\hline Best response & & & $0.016^{\mathrm{a}}$ \\
\hline $\mathrm{CR}$ & $1.0(2.0 \%)$ & $0.0(0.0 \%)$ & \\
\hline PR & $11.0(22.4 \%)$ & $9.0(13.8 \%)$ & \\
\hline $\mathrm{SD}$ & $27.0(55.1 \%)$ & $26.0(40.0 \%)$ & \\
\hline $\mathrm{PD}$ & $10.0(20.4 \%)$ & $30.0(46.2 \%)$ & \\
\hline PFS, months (range) & $10.0(7.0-16.0)$ & $6.0(4.0-8.0)$ & $0.004^{\mathrm{a}}$ \\
\hline OS, months (range) & 33.0 (27.0-NA) & $20.0(17.0-27.0)$ & $0.020^{\mathrm{a}}$ \\
\hline Adverse events & & & 0.900 \\
\hline Grade $1 / 2$ & $11.0(26.2 \%)$ & $14.0(26.4 \%)$ & \\
\hline Grade 3/4 & $31.0(73.8 \%)$ & $39.0(73.6 \%)$ & \\
\hline
\end{tabular}

Adverse events are graded according to Common Terminology Criteria for Adverse Events V.4.03. PS, performance status; CR, complete response; $\mathrm{PR}$, partial response; SD, stable disease; PD, progressive disease; PFS, progression-free survival; OS, overall survival; NA, not achieved. ${ }^{a} \mathrm{P}<0.05$.

Table III. Univariate analysis of factors associated with progression-free survival.

\begin{tabular}{lccr}
\hline Variable & HR & $95 \%$ CI & P-value \\
\hline Age <51 years & 1.12 & $0.74-1.68$ & 0.6000 \\
Dose reduction of palbociclib & 2.38 & $1.45-3.89$ & $<0.0002^{\mathrm{a}}$ \\
Baseline ALC $<1.5 \mathrm{~g} / 1$ & 1.71 & $1.13-2.60$ & $0.0115^{\mathrm{a}}$ \\
Occurrence of adverse events & 0.39 & $0.23-0.68$ & $0.0088^{\mathrm{a}}$ \\
$<5$ treatment lines & 0.41 & $0.26-0.63$ & $<0.0001^{\mathrm{a}}$ \\
\hline
\end{tabular}

${ }^{\mathrm{a}} \mathrm{P}<0.05$. ALC, absolute lymphocyte count.

$<5$ previous lines of treatment had a significantly longer PFS (9 vs. 5 months; $\mathrm{P}<0.0001$ ). Palbociclib dose reduction and the absence of AE were associated with worse PFS ( 6 vs. 8 months; $\mathrm{P}<0.0002$ and 4 vs. 8 months; $\mathrm{P}=0.0088$, respectively) (Table III). In multivariate analysis, age did not influence PFS. Lymphopenia and palbociclib dose reduction were associated with worse PFS [hazard ratio $(\mathrm{HR})=1.71$ (1.13-2.60); $\mathrm{P}=0.01$ and $\mathrm{HR}=2.38$ (1.45-3.89); $\mathrm{P}<0.001$, respectively]. Presence of $\mathrm{AE}$ and $<5$ previous lines of treatment were significantly associated with better PFS [HR=0.39 (0.23-0.68) and 0.41 (0.26-0.64), respectively; $\mathrm{P}<0.001)$ (Table IV).

OS was shorter in patients with lymphopenia.. Median OS in the whole population was 27 months. Patients with baseline lymphopenia had significantly shorter OS (20 vs. 33 months; log-rank $\mathrm{P}=0.018$; supremum log-rank $\mathrm{P}=0.013$; Fig. 1). In multivariate analysis, lymphopenia was independently
Table IV. Multivariate analysis of factors associated with overall survival.

\begin{tabular}{lccc}
\hline Variable & HR & 95\% CI & P-value \\
\hline Age <51 years & 0.79 & $0.48-1.30$ & 0.3485 \\
Dose reduction of palbociclib & 1.42 & $0.80-2.51$ & 0.2319 \\
Baseline ALC <1.5 g/l & 1.76 & $1.03-3.02$ & $0.0399^{a}$ \\
Occurrence of adverse events & 1.14 & $0.54-2.40$ & 0.7245 \\
$<5$ treatment lines & 0.72 & $0.42-1.26$ & 0.2517 \\
\hline
\end{tabular}

${ }^{a} \mathrm{P}<0.05$. ALC, absolute lymphocyte count.

associated with worse $\mathrm{OS}$ [HR=1.76 (1.02-3.02); $\mathrm{P}=0.04]$. Palbociclib dose reduction, occurrence of AE, age and number of lines of treatment did not have any impact on OS (Table III).

Response rate was lower in patients with lymphopenia. In the whole group, the ORR was $18.4 \%$ (21 patients), with CR achieved for one patient (1.7\%). A total of 53 patients (46.5\%) had SD. The PD rate was $35.1 \%$, resulting in a DCR of $64.9 \%$ (74 patients). There was significantly less partial response (13.8 vs. $22.4 \%$; $\mathrm{P}=0.016)$ and more disease progression at first disease evaluation (46.2 vs. $20.4 \%$; $\mathrm{P}=0.016)$ in patients with baseline ALC $<1.5 \mathrm{~g} / 1$ compared with those with ALC $\geq 1.5 \mathrm{~g} / 1$ (Table II).

Security data are compatible with those already known and reported in published phase 3 trials. The majority of patients experienced hematological toxicity, as expected. A total of 

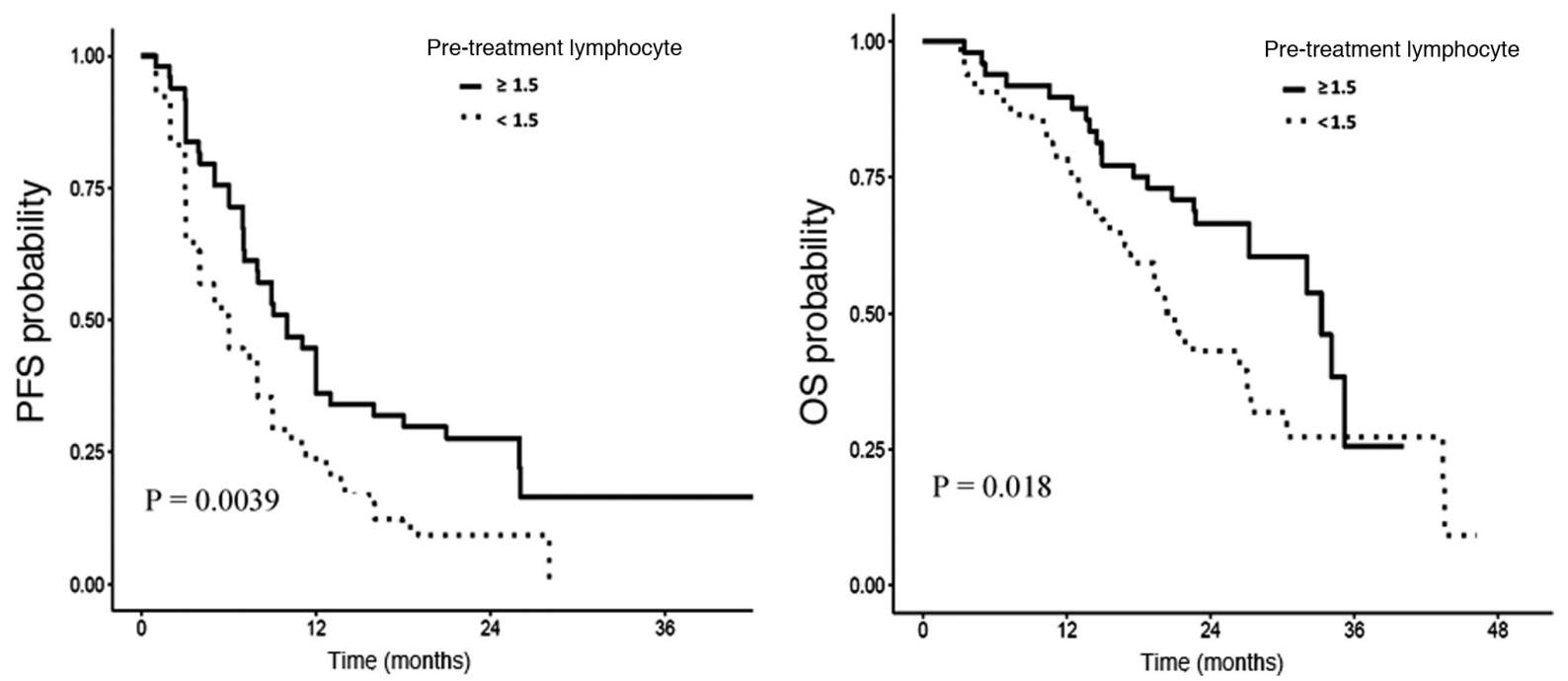

Figure 1. Kaplan-Meier plot comparing OS and PFS between patients with baseline lymphocytes $\geq 1.5$ and $<1.5 \mathrm{~g} / 1$. OS, overall survival; PFS, progression-free survival.

96 patients $(84.2 \%)$ experienced AE. The most common AE was neutropenia $(82.5 \%)$. More than $50 \%$ of patients had grade 3 or higher neutropenia and only one patient had febrile neutropenia. A total of eight patients (7\%) experienced thrombocytopenia.

\section{Discussion}

CDK4/6i and ET combinations are effective for most patients with $\mathrm{HR}^{+} / \mathrm{HER}^{-} \mathrm{mBC}(9)$, but certain patients fail to respond and no biomarker is currently available to predict response to treatment (20). To the best of our knowledge, the present study is the first that demonstrates an association between baseline lymphopenia and worse survival and response rate in this population.

The host immune system serves a key role in cancer control (21). Lymphocytes, whether in peripheral blood or as tumor-infiltrating lymphocytes, are key factors contributing to the body's immune response (22-24). Baseline lymphopenia has been shown to be a poor prognostic factor for various types of cancer (11-17). For example, in a study by Ray-Coquard et al (17), lymphopenia was found to be an independent prognostic factor for OS and PFS in mBC [relative risk (RR), 1.8 ; 95\% CI, 1.3-2.4], in advanced soft tissue sarcoma (RR, 1.46; 95\% CI, 1.0-2.1) and in non-Hodgkin's lymphoma (RR, 1.48; 95\% CI, 1.03-2.1). Lymphopenia is a powerful predictor of chemotherapy-induced toxicity and is also a predictive factor of the efficacy of chemotherapy in colorectal, breast and lung cancer (11,25-27).

Several studies have reported a worse ORR in patients with baseline lymphopenia compared with patients with normal ALC $(11,25-27)$, as seen in the present study. Here, disease progression was observed at the first evaluation in $46.2 \%$ of patients with baseline lymphopenia vs. $20.4 \%$ with normal ALC ( $\mathrm{P}=0.016)$. For $\mathrm{HR}^{+} / \mathrm{HER} 2^{-} \mathrm{BC}$, fewer data are available concerning the impact of lymphopenia on survival, although it is known that higher ALC is associated with better response to ET (28). Here, the majority of patients received fulvestrant (85\%); to the best of our knowledge, the type of ET does not influence ALC. More recently, it was reported that neutrophil-to-lymphocyte ratio is a predictive marker for response to ET in mBC (29). In the Ray-Coquard et al study (17) the ALC threshold was set at $1 \mathrm{~g} / 1$ to predict OS in different types of tumor. In the present study, OS and PFS were impacted regardless of ALC.

Tumor cells can elude immune surveillance. One of the mechanisms of this escape is the recruitment of immunosuppressive regulatory $\mathrm{T}$ lymphocytes (TLs) (30). The previous success of immunotherapy based on anti-cytotoxic TL-associated antigen 4 or anti-programmed death-1/programmed death ligand-1 antibodies confirms the relevance of TL-based anti-tumor immunity and suggests that restoration of the immune system could promote tumor control (31). Several animal and in vitro models have demonstrated the immune actions of CDK4/6i (32-34). CDK4/6i increase the immunogenicity of tumor cells (32) and enhance tumor infiltration via TL activation $(35,36)$. CDK4/6i enable reactivation of nuclear factor of activated $\mathrm{T}$ cell proteins and their target genes, including the gene encoding IL-2, a major cytokine that activates TL effectors (36). Finally, CDK4/6i may decrease the proliferation of regulatory TL $(32,36)$, reversing the balance of TL effectors and TL regulators in favor of tumor control. CDK4/6i also increase expression of genes involved in antigen processing and presentation in vivo in mouse and patient-derived xenograft models and suppress the proliferation of immune-suppressive regulatory TL, thus promoting cytotoxic TL-mediated tumor cell destruction (35). Lymphopenia may reflect $\mathrm{T}$ cell dysfunction with limited ability to perform antitumor functions and immune actions during palbociclib therapy (37).

Both host characteristics and a high tumor burden can result in lymphopenia (38). In a pooled series, lymphopenia was associated with patient age (39). Inflammation-induced cell death and decreased thymic function have been suggested as potential mechanisms of peripheral lymphopenia observed in patients with metastasis (40). In our study, median age and PS were similar in patients regardless of ALC. A possible explanation is that our population was young (median age was only 51 years). 
A large number of the patients in the present study were from the French Compassionate Access Program, which provides temporary authorization for use of unlicensed drugs outside of clinical trials to treat serious or rare diseases when no appropriate treatment exists. This program was implemented to improve early access to promising drugs (41). Thus patients were heavily pretreated, as in the Battisti et al study (42). This may explain the shorter PFS and OS in the present study compared with those reported in published registration studies (3-8). All patients received palbociclib because it was the first drug to have obtained marketing authorization in France. Lymphopenia was independent of the number of previous lines of treatment. Lymphopenia has been reported as a risk factor for the occurrence of chemotherapy-induced hematotoxicity, especially neutropenia, severe thrombocytopenia and anemia requiring transfusion and early death following chemotherapy $(17,25,26,43,44)$. ALC of $0.7 \mathrm{~g} / 1$ was previously identified as the most discriminative predictive value for hematological AE (45). Here, there was no association between baseline ALC and the probability of AE. Regarding dose reduction, the present results are consistent with previously published studies showing that reduce the dose of $\mathrm{CDK} 4 / 6 \mathrm{i}$ has a negative impact on treatment efficacy $(46,47)$.

A recent publication assessed the role of certain genomic markers in circulating tumor DNA to identify patients at higher risk of early progression following fulvestrant therapy in the presence or absence of palbociclib (48). The aforementioned study found that high-circulating tumor fraction, TP53 mutation and fibroblast growth factor receptor 1 amplification were associated with worse PFS even following the addition of CDK4/6i. Despite the interest in these genomic markers in prognostic estimation, they remain expensive and difficult to monitor in daily practice. The present study suggested that assessment of ALC, a routine and less expensive test, may serve as a significant prognostic factor for patients with $\mathrm{HR}^{+} / \mathrm{HER} 2^{-} \mathrm{mBC}$.

The present study had certain limitations, including the small sample size and retrospective single-center design. Due to lack of data, lactate dehydrogenase LDH dosage, an indicator of high tumor burden as suggested in another study (49), was not assessed. The present study did not have a long follow-up, however it was sufficient to obtain fairly discriminative survival information. Due to the limited sample size, retrospective design and heterogeneity of the population, other elements, such as markers of inflammation and CD4/8 TL count ratio could not be evaluated. The present results need to be confirmed by large-scale studies with extensive follow-up and assessment of other inflammation markers.

To the best of our knowledge, the present study is the first to demonstrate the impact of baseline lymphopenia as a strong and easy-to-use prognostic factor for patients with $\mathrm{HR}^{+} / \mathrm{HER} 2-\mathrm{mBC}$ treated with palbociclib in combination with ET. Lymphopenia may also be a predictive factor of early progression. A larger study is needed to confirm these results.

\section{Acknowledgements}

Not applicable.

\section{Funding}

No funding was received.

\section{Availability of data and materials}

The datasets used and/or analyzed during the current study are available from the corresponding author on reasonable request.

\section{Authors' contributions}

GE was responsible for the conception and design of the study. GE, SP and ADS collected the data and wrote the manuscript. GE and ADS confirm the authenticity of all the raw data. JL performed statistical analysis, participated in data analysis, interpreted the data and wrote the manuscript. GE, SP, ADS, CL, AJ, DA, IH, CS, AM, KG, AF and FC interpreted the data and wrote the manuscript. All authors read and approved the final manuscript.

\section{Ethics approval and consent to participate}

In accordance with the regulations regarding research involving human subjects, the present study was registered with corresponding data protection. Patients' non-opposition to the use of their data was sought after verification of their vital status.

\section{Patient consent for publication}

Not applicable.

\section{Competing interests}

The authors declare that they have no competing interests.

\section{References}

1. Bray F, Ferlay J, Soerjomataram I, Siegel RL, Torre LA and Jemal A: Global cancer statistics 2018: GLOBOCAN estimates of incidence and mortality worldwide for 36 cancers in 185 countries. CA Cancer J Clin 68: 394-424, 2018.

2. Cardoso F, Paluch-Shimon S, Senkus E, Curigliano G, Aapro MS, André F, Barrios CH, Bergh J, Bhattacharyya GS, Biganzoli L, et al: 5th ESO-ESMO international consensus guidelines for advanced breast cancer (ABC 5). Ann Oncol 31: 1623-1649, 2020.

3. Finn RS, Crown JP, Lang I, Boer K, Bondarenko IM, Kulyk SO, Ettl J, Patel R, Pinter T, Schmidt M, et al: The cyclin-dependent kinase 4/6 inhibitor palbociclib in combination with letrozole versus letrozole alone as first-line treatment of oestrogen receptor-positive, HER2-negative, advanced breast cancer (PALOMA-1/TRIO-18): A randomised phase 2 study. Lancet Oncol 16: 25-35, 2015.

4. Cristofanilli M, Turner NC, Bondarenko I, Ro J, Im SA, Masuda N, Colleoni M, DeMichele A, Loi S, Verma S, et al: Fulvestrant plus palbociclib versus fulvestrant plus placebo for treatment of hormone-receptor-positive,HER2-negative metastatic breast cancer that progressed on previous endocrine therapy (PALOMA-3): Final analysis of the multicentre, double-blind, phase 3 randomised controlled trial. Lancet Oncol 17: 425-439, 2016.

5. Hortobagyi GN, Stemmer SM, Burris HA, Yap YS, Sonke GS, Paluch-Shimon S, Campone M, Petrakova K, Blackwell KL, Winer EP, et al: Updated results from MONALEESA-2, a phase III trial of first-line ribociclib plus letrozole versus placebo plus letrozole in hormone receptor-positive, HER2-negative advanced breast cancer. Ann Oncol 29: 1541-1547, 2018. 
6. Slamon DJ, Neven P, Chia S, Fasching PA, De Laurentiis M, Im SA, Petrakova K, Bianchi GV, Esteva FJ, Martín M, et al: Phase III randomized study of ribociclib and fulvestrant in hormone receptor-positive, human epidermal growth factor receptor 2-negative advanced breast cancer: MONALEESA-3. J Clin Oncol 36: 2465-2472, 2018

7. Goetz MP, Toi M, Campone M, Sohn J, Paluch-Shimon S, Huober J, Park IH, Trédan O, Chen SC, Manso L, et al: MONARCH 3: Abemaciclib as initial therapy for advanced breast cancer. J Clin Oncol 35: 3638-3646, 2017.

8. Sledge GW Jr, Toi M, Neven P, Sohn J, Inoue K, Pivot X, Burdaeva O, Okera M, Masuda N, Kaufman PA, et al: The effect of abemaciclib plus fulvestrant on overall survival in hormone receptor-positive, ERBB2-negative breast cancer that progressed on endocrine therapy-MONARCH 2: A Randomized Clinical Trial. JAMA Oncol 6: 116-124, 2020.

9. Schettini F, Giudici F, Giuliano M, Cristofanilli M, Arpino G, Del Mastro L, Puglisi F, De Placido S, Paris I, De Placido P, et al: Overall survival of CDK4/6-inhibitor-based treatments in clinically relevant subgroups of metastatic breast cancer: Systematic review and meta-analysis. J Natl Cancer Inst 112: 1089-1097, 2020.

10. Migliaccio I, Leo A, Galardi F, Guarducci C, Fusco GM, Benelli M, Di Leo A, Biganzoli L and Malorni L: Circulating biomarkers of CDK4/6 inhibitors response in hormone receptor positive and HER2 negative breast cancer. Cancers (Basel) 13: 2640, 2021.

11. Cézé N, Thibault G, Goujon G, Viguier J, Watier H, Dorval E and Lecomte T: Pre-treatment lymphopenia as a prognostic biomarker in colorectal cancer patients receiving chemotherapy. Cancer Chemother Pharmacol 68: 1305-1313, 2011.

12. Grossman SA, Ye X, Lesser G, Sloan A, Carraway H, Desideri S and Piantadosi S; NABTT CNS Consortium: Immunosuppression in patients with high-grade gliomas treated with radiation and temozolomide. Clin Cancer Res 17: 5473-5480, 2011.

13. Balmanoukian A, Ye X, Herman J, Laheru D and Grossman SA: The association between treatment-related lymphopenia and survival in newly diagnosed patients with resected adenocarcinoma of the pancreas. Cancer Invest 30: 571-576, 2012

14. He JR, Shen GP, Ren ZF, Qin H, Cui C, Zhang Y, Zeng YX and Jia WH: Pretreatment levels of peripheral neutrophils and lymphocytes as independent prognostic factors in patients with nasopharyngeal carcinoma. Head Neck 34: 1769-1776, 2012.

15. Kobayashi N, Usui S, Kikuchi S, Goto Y, Sakai M, Onizuka M and Sato Y: Preoperative lymphocyte count is an independent prognostic factor in node-negative non-small cell lung cancer. Lung Cancer 75: 223-227, 2012.

16. Feng JF, Liu JS and Huang Y: Lymphopenia predicts poor prognosis in patients with esophageal squamous cell carcinoma. Medicine (Baltimore) 93: e257, 2014.

17. Ray-Coquard I, Cropet C, Van Glabbeke M, Sebban C, Le Cesne A, Judson I, Tredan O, Verweij J, Biron P, Labidi I, et al; European Organization for Research and Treatment of Cancer Soft Tissue and Bone Sarcoma Group: Lymphopenia as a prognostic factor for overall survival in advanced carcinomas, sarcomas, and lymphomas. Cancer Res 69: 5383-5391, 2009.

18. Schwartz LH, Seymour L, Litière S, Ford R, Gwyther S Mandrekar S, Shankar L, Bogaerts J, Chen A, Dancey J, et al: RECIST 1.1 - Standardisation and disease-specific adaptations: Perspectives from the RECIST Working Group. Eur J Cancer 62: 138-145, 2016

19. US Department of Health and Human Services: Common Terminology Criteria for Adverse Events (CTCAE).v.5.0. Natl Institutes Heal Natl Cancer Institute, p155, 2017.

20. Garrido-Castro AC and Goel S: CDK4/6 inhibition in breast cancer: Mechanisms of response and treatment failure. Curr Breast Cancer Rep 9: 26-33, 2017.

21. Dunn GP, Bruce AT, Ikeda H, Old LJ and Schreiber RD: Cancer immunoediting: From immunosurveillance to tumor escape. Nat Immunol 3: 991-998, 2002.

22. Rosenberg SA: The immunotherapy of solid cancers based on cloning the genes encoding tumor-rejection antigens. Annu Rev Med 47: 481-491, 1996

23. Bates GJ, Fox SB, Han C, Leek RD, Garcia JF, Harris AL and Banham AH: Quantification of regulatory $\mathrm{T}$ cells enables the identification of high-risk breast cancer patients and those at risk of late relapse. J Clin Oncol 24: 5373-5380, 2006.

24. Schreiber RD, Old L and Smyth MJ: Cancer immunoediting: Integrating immunity's roles in cancer suppression and promotion. Science 331: 1565-7150, 2011.
25. Ray-Coquard I, Ghesquière $\mathrm{H}$, Bachelot $\mathrm{T}$, Borg C, Biron $\mathrm{P}$ Sebban C, LeCesne A, Chauvin F and Blay JY; ELYPSE Study Group: Identification of patients at risk for early death after conventional chemotherapy in solid tumours and lymphomas. $\mathrm{Br}$ J Cancer 85: 816-822, 2001.

26. Ray-Coquard I, Borg C, Bachelot T, Sebban C, Philip I, Clapisson G, Le Cesne A, Biron P, Chauvin F and Blay JY; ELYPSE study group: Baseline and early lymphopenia predict for the risk of febrile neutropenia after chemotherapy. Br J Cancer 88: 181-186, 2003

27. Lissoni P, Brivio F, Fumagalli L, Messina G, Ghezzi V, Frontini L, Giani L, Vaghi M, Ardizzoia A and Gardani GS: Efficacy of cancer chemotherapy in relation to the pretreatment number of lymphocytes in patients with metastatic solid tumors. Int J Biol Markers 19: 135-140, 2004.

28. Franks CR and Williams Y: Prognostic value of peripheral lymphocyte count in hormone therapy of advanced breast cancer. Br J Cancer 34: 641-644, 1976.

29. Limori N, Shinichiro K, Yuka A, Wataru G, Koji T, Katsuyuki T and Takaharu H: Clinical significance of the neutrophil-to-lymphocyte ratio in endocrine therapy for stage IV breast cancer. In Vivo 32: 669-675, 2018.

30. Gobert M, Treilleux I, Bendriss-Vermare N, Bachelot T, GoddardLeon S, Arfi V, Biota C, Doffin AC, Durand I, Olive D, et al: Regulatory $\mathrm{T}$ cells recruited through CCL22/CCR4 are selectively activated in lymphoid infiltrates surrounding primary breast tumors and lead to an adverse clinical outcome. Cancer Res 69: 2000-2009, 2009.

31. Yang Y: Cancer immunotherapy: Harnessing the immune system to battle cancer. J Clin Invest 125: 3335-3337, 2015.

32. Goel S, DeCristo MJ, Watt AC, BrinJones H, Sceneay J, Li BB, Khan N, Ubellacker JM, Xie S, Metzger-Filho O, et al: CDK4/6 inhibition triggers anti-tumour immunity. Nature 548: 471-475, 2017.

33. Lelliott EJ, Kong IY, Zethoven M, Ramsbottom KM, Martelotto LG, Meyran D, Zhu JJ, Costacurta M, Kirby L, Sandow JJ, et al: CDK4/6 inhibition promotes antitumor immunity through the induction of T-cell memory. Cancer Discov: May 14, 2021. doi: 10.1158/2159-8290.CD-20-1554.

34. Zhang QF, Li J, Jiang K, Wang R, Ge JL, Yang H, Liu SJ, Jia LT, Wang L and Chen BL: CDK4/6 inhibition promotes immune infiltration in ovarian cancer and synergizes with PD-1 blockade in a B cell-dependent manner. Theranostics 10: 10619-10633, 2020.

35. Teh JL and Aplin AE: Arrested developments: CDK4/6 inhibitor resistance and alterations in the tumor immune microenvironment. Clin Cancer Res 25: 921-927, 2019.

36. Deng J, Wang ES, Jenkins RW, Li S, Dries R, Yates K, Chhabra S, Huang W, Liu H, Aref AR, et al: CDK4/6 inhibition augments antitumor immunity by enhancing T-cell activation. Cancer Discov 8: 216-233, 2018.

37. Williams KM, Hakim FT and Gress RE: T cell immune reconstitution following lymphodepletion. Semin Immunol 19: 318-330, 2007.

38. Ménétrier-Caux C, Ray-Coquard I, Blay JY and Caux C: Lymphopenia in cancer patients and its effects on response to immunotherapy: An opportunity for combination with Cytokines? J Immunother Cancer 7: 85, 2019.

39. Ferrando-Martínez S, Franco JM, Hernandez A, Ordoñez A, Gutierrez E, Abad A and Leal M: Thymopoiesis in elderly human is associated with systemic inflammatory status. Age (Dordr) 31: 87-97, 2009.

40. Manuel M, Tredan O, Bachelot T, Clapisson G, Courtier A, Parmentier G, Rabeony T, Grives A, Perez S, Mouret JF, et al: Lymphopenia combined with low TCR diversity (divpenia) predicts poor overall survival in metastatic breast cancer patients. OncoImmunology 1: 432-440, 2012

41. Degrassat-Théas A, Paubel P, Parent de Curzon O, Le Pen C and Sinègre M: Temporary authorization for use: Does the French patient access programme for unlicensed medicines impact market access after formal licensing? PharmacoEconomics 31: 335-343, 2013.

42. Battisti NM, Kingston B, King J, Denton A, Waters S, Sita-Lumsden A, Rehman F, Stavraka C, Kristeleit H, Sawyer E, et al: Palbociclib and endocrine therapy in heavily pretreated hormone receptor-positive HER2-negative advanced breast cancer: The UK Compassionate Access Programme experience. Breast Cancer Res Treat 174: 731-740, 2019.

43. Blay J, Ray-Coquard I and Mermet C: A multicentric prospective study of prognostic factors for febrile neutropenia after chemotherapy in general and cancer hospitals. J Clin Oncol 16: 56a, 1997. 
44. Blay JY, Le Cesne A, Mermet C, Maugard C, Ravaud A, Chevreau C, Sebban C, Guastalla J, Biron P and Ray-Coquard I: A risk model for thrombocytopenia requiring platelet transfusion after cytotoxic chemotherapy. Blood 92: 405-410, 1998.

45. Borg C,Ray-Coquard I,Philip I,Clapisson G,Bendriss-VermareN, Menetrier-Caux C, Sebban C, Biron P and Blay JY: CD4 lymphopenia as a risk factor for febrile neutropenia and early death after cytotoxic chemotherapy in adult patients with cancer. Cancer 101: 2675-2680, 2004.

46. Moftakhar B, Lekkala M, Strawderman M, Smith TC, Meacham P, Fitzgerald B, Falkson CI and Dhakal A: Impact of early dose intensity reduction of Palbociclib on clinical outcomes in patients with hormone-receptor-positive metastatic breast cancer. Breast Cancer Res Treat 183: 411-418, 2020.
47. Groenland SL, Martínez-Chávez A, van Dongen MG, Beijnen JH, Schinkel AH, Huitema AD and Steeghs N: Clinical Pharmacokinetics and Pharmacodynamics of the Cyclin-Dependent Kinase 4 and 6 Inhibitors Palbociclib, Ribociclib, and Abemaciclib. Clin Pharmacokinet 59: 1501-1520, 2020.

48. O'Leary B, Cutts RJ, Huang X, Hrebien S, Liu Y, André F, Loibl S, Loi S, Garcia-Murillas I, Cristofanilli M, et al: Circulating tumor DNA markers for early progression on fulvestrant with or without palbociclib in $\mathrm{ER}^{+}$advanced breast cancer. J Natl Cancer Inst 113: 309-317, 2021.

49. Che YQ, Zhang Y, Wang D, Liu H-Y, Shen D and Luo Y: Baseline lymphopenia: A predictor of poor outcomes in HER2 positive metastatic breast cancer treated with trastuzumab. Drug Des Devel Ther 13: 3727-3734, 2019. 